\title{
Pulmonary Valve Atresia with Ventricular Septal Defect
}

National Cancer Institute

\section{Source}

National Cancer Institute. Pulmonary Valve Atresia with Ventricular Septal Defect. NCI

Thesaurus. Code C99033.

Pulmonary valve atresia associated with the presence of a large ventricular septal defect.

It may be a severe form of tetralogy of Fallot. 